\title{
Aging of the Innate Immune System
}

\author{
Albert C. Shaw ${ }^{1}$, Samit Joshi ${ }^{1}$, Hannah Greenwood ${ }^{2}$, Alexander Panda ${ }^{1}$, and Janet M. Lord ${ }^{2}$ \\ Albert C. Shaw: albert.shaw@yale.edu; Samit Joshi: samit.joshi@yale.edu; Hannah Greenwood: hxg985@bham.ac.uk; \\ Alexander Panda: alexander.panda@yale.edu; Janet M. Lord: J.M.Lord@bham.ac.uk \\ ${ }^{1}$ Section of Infectious Diseases, Department of Internal Medicine, Yale School of Medicine, 300 \\ Cedar St. Box 208022, New Haven, CT, 06520 USA \\ ${ }^{2}$ MRC Centre for Immune Regulation, School of Immunity and Infection, University of \\ Birmingham, Birmingham B15 2TT, UK
}

\section{Summary}

\begin{abstract}
The innate immune system is composed of a network of cells including neutrophils, NK and NKT cells, monocytes/macrophages, and dendritic cells that mediate the earliest interactions with pathogens. Age-associated defects are observed in the activation of all of these cell types, linked to compromised signal transduction pathways including the Toll-like Receptors. However, aging is also characterized by a constitutive pro-inflammatory environment (Inflamm-aging) with persistent low-grade innate immune activation that may augment tissue damage caused by infections in elderly individuals. Thus, immunosenescence in the innate immune system appears to reflect dysregulation, rather than exclusively impaired function.
\end{abstract}

\section{Introduction}

Immunosenescence in the innate immune system has considerable complexity. For example, in a mouse model of influenza infection slower recovery, prolonged morbidity, and longer duration of viremia were observed in older C57BL/6 mice, but were associated with a wide range of responses ranging from a delay in granulocyte and conventional DCs (cDCs) infiltration to the lungs, to increased macrophage persistence in the lung. Production of proinflammatory compounds such as IL-12 and MCP-1 in the lung were diminished in old mice, but for others such as IL-6 a delayed peak was observed, while TNF- $a$ and IL-1a levels were higher [1]. Thus, while many responses in the innate immune system are diminished with aging, there is substantial evidence for age-associated hyper-reactivity of innate immunity as well. The effects of aging on the innate immune system in humans and mice have been reviewed recently [2-4]; here, we provide an overview emphasizing recent developments in the field.

\section{Neutrophils}

Neutrophils constitute the primary immune defense against rapidly dividing bacteria, yeast and fungal infections, deploying microbicidal mechanisms including generation of reactive oxygen and nitrogen species, release of proteolytic enzymes and microbicidal peptides from 
cytoplasmic granules. Neutrophils can also engage and kill microbes extracellularly through the extrusion of Neutrophil Extracellular Traps (NETs) [5]. To date there are no reports concerning NET production by neutrophils from older adults, though NET generation is reduced in neonates compared to adults, indicating that this aspect of neutrophil function is modified through development [6]. Cells of the immune system are derived from haematopoietic stem cells (HSCs) which proliferate and commit to either lymphoid or myeloid lineages. With increasing age, there is a skewing towards myeloid progenitors at the expense of lymphoid progenitors. Beerman et al have shown recently that this is the result of the clonal expansion of myeloid biased HSCs [7•]. There is thus no reduction in neutrophil numbers with age and no loss of ability to generate a robust neutrophilia in response to infection. In contrast, human neutrophils show compromised activity with aging, with most aspects of neutrophil microbicidal function affected. The reduced chemotactic ability seen in neutrophils from older donors [8] would affect the time taken for neutrophils to reach the site of infection allowing rapidly dividing bacteria to establish a strong core of infection. Inefficient chemotaxis would also increase bystander tissue damage as neutrophils secrete proteases such as elastase to aid their migration through tissues. The latter would be expected to extend inflammation and impair resolution of inflammation in older adults. Nomellini et al assessed neutrophil accumulation in the lungs of young and old mice following burn injury. They showed the rate of neutrophil accumulation did not differ with age, but the time taken to resolve the inflammation was significantly longer in the old mice suggestive of greater tissue damage [9•]. Chemotaxis is also the mechanism by which effete neutrophils return to the bone marrow at the end of their short lifespan following upregulation of CXCR4 [10]. Whether the return of effete neutrophils to the bone marrow is also affected by aging is not known, but we suggest that this is a possibility. Neutrophils aged in vitro gradually senesce and show reduced phagocytosis and superoxide generation prior to entry into apoptosis. If the removal of older effete neutrophils from the circulation is impeded they would remain in the blood for longer thus reducing average neutrophil function (Figure 1).

For some aspects of age-related neutrophil decline the mechanisms are partially understood, for example reduced phagocytosis of opsonised $E$. Coli is associated with reduced surface expression of the Fc $\gamma$ receptor CD16 [11]. However for most other aspects of neutrophil senescence our understanding is incomplete. Aging affects a broad range of cellular processes in the neutrophil, mediated by ligation of receptors with distinct signaling mechanisms. With the exception of CD16, the literature shows that expression of receptors mediating neutrophil activation is unaltered with age. As a broad range of downstream signaling events employed by these receptors are affected by aging, including altered calcium, Phosphoinositide-3 kinase (PI-3K), MAP kinase, Protein Kinase B, Jak-STAT and SHP-1 signaling (reviewed in [12]), this suggests that changes to generic signaling processes are most likely to underlie these observations.

Lipid rafts are crucial for the efficient functioning of many membrane bound receptors, facilitating formation of multimeric signaling complexes. Changes to the composition of membrane lipids crucial for lipid raft structure, for example by depletion of cholesterol, compromises receptor mediated signaling and could explain the multiple age-related 
changes in neutrophil receptor signaling. A single report examining rat peritoneal neutrophils revealed an age-dependent increase in membrane fluidity associated with a decline in the cholesterol/phospholipid ratio and a rise in total polyunsaturated fatty acids [13]. Crucially, neutrophils from 24 month old rats had a dramatically reduced superoxide burst in response to fMLP that was overcome when cells were treated with phorbol myristate (PMA), supporting our proposal that the age-related loss of neutrophil function is due at least in part to compromised proximal signaling events. Further support for this proposal is provided by Fortin $e t$ al who reported that recruitment of Triggering Receptor Expressed on Myeloid cells-1 (TREM-1) to lipid rafts was reduced in neutrophils from elderly donors, with concomitant reduction in downstream signaling events [14]. As TREM-1 regulates TLR signaling, this observation may also help to explain data showing reduced levels of TLR4 in lipid raft fractions in response to lipopolysaccharide in neutrophils from elderly donors [15].

\section{NK and NKT cells}

NK cells mediate MHC-independent cytotoxicity in the innate immune defense against viral infections and some malignancies. Absolute numbers of NK cells increase with age, reflecting an increase in CD56dim cells, but NK cell cytotoxicity on a per cell basis is decreased and levels of cytokines and chemokines such as RANTES, MIP1a, and IL-8 produced upon NK cell activation are also reduced (reviewed in [16]). These age-associated alterations in NK function may result in part from changes in zinc homeostasis in older individuals, and there is evidence that NK cell function can be improved with zinc supplementation [17]. A recent report postulated a more direct link between NK cells and reduced adaptive immunity. In aged Balb/c mice, an increased proportion of NK cells were found in an early B cell bone marrow developmental population (Hardy Fraction A); depletion experiments revealed that this NK population may directly inhibit surrogate light chain expression in developing B cells, thereby potentially contributing to B cell immunosenescence [18•].

Classical NKT cells express a T cell receptor (Va14/V $\beta 8.2$ in mice and Va24/V $\beta 11$ in humans) that is CD1d-restricted and represent a rare class of "innate immune lymphocyte". Studies in mice have demonstrated an age-associated increase in NKT cell numbers with augmented function [19-21]. A role for NKT cells in modulating the inflammatory response to viral infection has emerged from a study by Stout-Delgado et al which employed a Herpes Simplex Virus-2 (HSV-2) murine infection system. Such infection resulted in markedly elevated levels of IL-17A in older, compared to young mice, and was associated with increased neutrophil recruitment to the liver and chemokine production. Notably, NKT cells from aged mice were identified as greater producers of elevated IL-17A levels compared to young NKT cells, and adoptive transfer of aged NKT cells into young mice resulted in hepatic injury [22••]. This concept of an enhanced inflammatory environment with aging has also been associated with augmented IL-17-dependent $\mathrm{T}$ cell allogeneic responses [23], and with an increase in IL23/p19 gene expression in aged murine bone marrow-derived dendritic cells [24•]; such hyper-responsive inflammatory responses could well contribute to adverse outcomes associated with infection or sepsis in older individuals. 


\section{Monocytes and Macrophages}

Monocytes represent a highly mobile component of the innate immune system located in the spleen and blood which respond to inflammation by differentiating into antigen presenting cells such as macrophages and dendritic cells. Monocyte absolute numbers increase with age [25], a change independently associated with clinical frailty [25a]. This increase in monocyte numbers is contrasted with an age-associated decrease in macrophage function, particularly in the context of Toll-like Receptor (TLR) activation. Age-associated decreases in LPS-induced (activating TLR4) IL-6, TNF- $\alpha$ and IL-1 $\beta$ have been reported in both C57BL/6 and Balb/c mice [26-28], and a more generalized decrease in cytokine production in response to activation of TLR2/6, 3, 4, 5, and 9 was observed in splenic and peritoneal macrophages from C57BL/6 mice [29] that was associated with decreased TLR gene expression. However, in aged Balb/c mice, decreased TLR signal transduction for example via MAP and JNK kinase pathways, rather than decreased TLR expression, was reported $[26,27,30]$. Similar defects in signal transduction and increased oxidative stress were observed in macrophages from both telomerase-deficient and aged wild-type mice [31].

Human studies of TLR function in monocytes have also revealed age-associated declines in cytokine production. A study of 79 young (age 21-30) and 80 older (age 265 ) subjects revealed an age-associated decrease in TLR1/2-induced IL- 6 and TNF-a production in monocytes [32]. Impairment in TLR1/2 function was associated with decreased monocyte surface expression of TLR1 but not TLR2; notably, intracellular TLR1 expression was unchanged, suggesting a post-translational alteration in surface TLR1 expression in monocytes from older individuals. A generalized age-associated defect in the upregulation of the co-stimulatory protein CD80 on monocytes was observed for all TLR ligands tested (TLR1/2, TLR/2/6, TLR4, TLR5, and TLR8) [33]. Crucially, the ability to increase CD80 expression upon TLR engagement was strongly associated with the generation of a protective antibody response to influenza vaccination, confirming consequences for adaptive immunity.

Defects in macrophage function in aged humans have also been described in a recent study evaluating delayed type hypersensitivity (DTH) responses to Candida antigens, which are known to diminish with age [34••]. Using skin biopsy specimens from young ( $<40$ years) and older ( $>70)$ individuals, substantial decreases in TNF- $a$, IL-6 and IFN- $\gamma$ levels were found in skin suction blister fluid samples from old, compared to young individuals. Decreased intracellular production of TNF- $a$ was observed in dermal macrophages, potentially contributing to decreased migration of $\mathrm{T}$ cells in response to antigen challenge in the skin. Since dermal macrophages from older individuals could be induced to produce TNF-a ex vivo, macrophage dysfunction in the skin of older individuals may reflect alterations in the skin microenvironment. These findings have implications for cutaneous innate immunity, as well as for the use of DTH in clinical contexts, such as tuberculin skin testing.

By contrast, other studies suggest that aging is associated with a pro-inflammatory environment-so-called "inflamm-aging" (reviewed elsewhere in this issue)—characterized by constitutively elevated levels of cytokines such as IL-6 and TNF- $a$ as well as acute phase 
reactants [35]. Dysregulation of TLR responses, as has been reported for the increased TLR3 expression observed following infection of aged human macrophages with West Nile Virus, may contribute to morbidity from viral infections in elderly individuals [36•]. In murine models of sepsis using either LPS intraperitoneal injection (Balb/c) or cecal ligation and puncture $(\mathrm{FVB} / \mathrm{N})$, aged mice were found to have an enhanced inflammatory response, as measured by cytokine and chemokine production or neutrophil infiltration, compared to young mice [37-39]. Notably, mice deficient in macrophage migration inhibitory factor (MIF), a cytokine with protean influences on inflammation, insulin signaling and cell cycle regulation, were recently found to have increased lifespan [40••]. Thus, it is conceivable that age-associated ex vivo defects in macrophage cytokine production can be reconciled with a pro-inflammatory milieu that may result in enhanced basal levels of cytokines and chemokines.

\section{Dendritic cells}

In general, aging results in decreased DC function, but some parameters may be unchanged and some examples of enhanced function have been reported. In murine systems, an ageassociated decrease in DC-SIGN expression was observed on immature bone marrow derived DCs [41]; but, myeloid splenic and bone marrow-derived DCs have preserved function in T cell priming and TLR function in aged mice [42]. Some defects in mDCs from aged mice have been observed in the context of a murine tumor antigen model, characterized by defective DC trafficking and impaired CCR7 signal transduction [43]. The function of pDCs isolated from bone marrow appeared compromised in aged C57BL/6 mice using an HSV-2 infection model dependent on TLR9 activation [44•]. Decreased production of IFNa upon HSV-2 infection was observed in pDCs from old mice, with defective induction of IRF-7 expression upon TLR9 activation. These findings potentially provide an additional basis for the impaired control of viral infections observed in aging individuals. An additional area for investigation is the follicular dendritic cell (FDC), a reticular cell present in primary and secondary follicles that is particularly adept at presenting immune complexes to facilitate B cell adaptive responses [45]. FDC networks in aged mice are markedly disrupted, and likely contribute to B cell immunosenescence, but FDC contribution to human immunosenescence remains poorly understood [46,47].

In humans, a recent study of 18 young and 19 older individuals elucidated an age-associated defect in TLR-7 and TLR-9-induced IFN-a production in pDCs, as assessed via intracellular cytokine staining [48]; no age-associated alterations in $\mathrm{mDC}$ cytokine production were observed, but mDC TLR function in this case was interrogated via cytokine ELISA of pooled young or older PBMCs. Panda et al carried out a study of TLR-induced cytokine production in 52 young (21-30) and 52 older ( 765 ) individuals, using intracellular staining to quantify cytokine levels in primary $\mathrm{mDCs}$ and pDCs [49॰]. An age-associated decrease in TLR7 and TLR9-induced IFN-a production was observed in pDCs and a generalized ageassociated defect in the intracellular production of TNF- $a$, IL-6 and the p40 subunit shared by IL-12 and IL-23 was observed for virtually all TLRs evaluated (TLR1/2, TLR2/6, TLR3, TLR4, TLR5, and TLR8). The extent of TLR-induced cytokine production was strongly associated with influenza vaccine antibody response. Notably, elevated basal levels of intracellular cytokine production were observed in older, but not young mDCs and pDCs. 
Thus, it is attractive to speculate that the observed TLR functional defects reflect a constitutive level of cytokine production that may contribute to an age-related proinflammatory environment, but cannot be substantially increased with additional TLR engagement.

In this context, monocyte derived DCs from older, compared to young individuals were found to have increases in LPS and single-stranded RNA-induced TNF- $a$ and IL-6 production, as well as increased self-DNA-induced IL- 6 and IFN-a production [50,51•]. These functional increases in cytokine output were accompanied by impairments in phagocytic function and migration in vitro, and were hypothesized to be attributable to diminished PI-3K activity, which has been implicated in both DC migration and as a possible negative regulator of TLR signaling. It remains possible that the growth factor treatment used to derive DCs from monocytes could attenuate age-associated functional differences; alternatively, this class of DC could model inflammatory DCs derived in vivo at the sites of infection-potentially another contributing factor to inflamm-aging.

\section{Extrinsic moderation of innate immune function}

When considering the immune system and the impact of aging upon its function, it is important to remember that it does not operate in isolation. It is now accepted that immunity is modulated by a plethora of hormones, including adrenal steroids, sex hormones and the expanding family of adipokines. As aging is associated with dramatic changes to the hormonal environment, this in turn will contribute to individual variability in immune decline.

Aging is accompanied by profound changes to the hypothalamic-pituitary-adrenal axis, termed the adrenopause. From the age of approximately 30 years the serum level of dehydroepiandrosterone sulfate (DHEAS) declines steadily until by the age of 70 only 10 $20 \%$ of maximal levels remain. In contrast cortisol levels are maintained throughout life. DHEAS primarily functions as a precursor to the androgenic hormone DHEA, but there is evidence that DHEA and DHEAS also have immune enhancing functions. Although this area is still quite controversial, the reported effects of these steroids include in vitro potentiation of monocyte, neutrophil and NK cell function and increased protection from bacterial infection in mice [52]. Interestingly, Radford et al have shown recently that neutrophils appear to be unique in their ability to respond to DHEAS as they were the only leukocytes to express a membrane transporter (OATP-D) for this sulfated steroid [53]. There are thus potential consequences for immunity in old age at times of stress as the increased production of the immune suppressive cortisol will not be counterbalanced by DHEA/ DHEAS. An increased cortisol:DHEAS ratio is seen after physical trauma (hip fracture) in older adults and is associated with reduced neutrophil superoxide generation and increased risk of infection [54]. Investigation into these and other extrinsic factors such as host functional status, together with the evaluation of age effects on other innate pattern recognition receptors such as the NOD-like and RIG-I-like receptors will lend further insights to future studies of age-associated changes in innate immunity. 


\section{Acknowledgments}

We apologize to members of the scientific community whose contributions could not be cited secondary to space limitations. Supported by the National Institute on Aging AG019134 (S.J), National Institute for Allergy and Infectious Disease NO150031 (to A.C.S.) and the Biotechnology and Biological Sciences Research Council (H.G).

\section{References}

1. Toapanta FR, Ross TM. Impaired immune responses in the lungs of aged mice following influenza infection. Respir Res. 2009; 10:112. [PubMed: 19922665]

2. Gomez CR, Nomellini V, Faunce DE, Kovacs EJ. Innate immunity and aging. Exp Gerontol. 2008; 43:718-728. [PubMed: 18586079]

3. Kovacs EJ, Palmer JL, Fortin CF, Fulop T Jr, Goldstein DR, Linton PJ. Aging and innate immunity in the mouse: impact of intrinsic and extrinsic factors. Trends Immunol. 2009; 30:319-324. [PubMed: 19541536]

4. Panda A, Arjona A, Sapey E, Bai F, Fikrig E, Montgomery RR, Lord JM, Shaw AC. Human innate immunosenescence: causes and consequences for immunity in old age. Trends Immunol. 2009; 30:325-333. [PubMed: 19541535]

5. Brinkmann V, Reichard U, Goosmann C, Fauler B, Uhlemann Y, Weiss DS, Weinrauch Y, Zychlinsky A. Neutrophil extracellular traps kill bacteria. Science. 2004; 303:1532-1535. [PubMed: 15001782]

6. Yost CC, Cody MJ, Harris ES, Thornton NL, McInturff AM, Martinez ML, Chandler NB, Rodesch CK, Albertine KH, Petti CA, et al. Impaired neutrophil extracellular trap (NET) formation: a novel innate immune deficiency of human neonates. Blood. 2009; 113:6419-6427. [PubMed: 19221037]

7. Beerman I, Bhattacharya D, Zandi S, Sigvardsson M, Weissman IL, Bryder D, Rossi DJ. Functionally distinct hematopoietic stem cells modulate hematopoietic lineage potential during aging by a mechanism of clonal expansion. Proc Natl Acad Sci U S A. 2010; 107:5465-5470. [PubMed: 20304793] This study reveals that the well documented skewing of haemopoiesis towards myeloid cells during aging is mediated by clonal expansion of myeloid specific heamopoietic stem cells.

8. Wenisch C, Patruta S, Daxbock F, Krause R, Horl W. Effect of age on human neutrophil function. J Leukoc Biol. 2000; 67:40-45. [PubMed: 10647996]

9. Nomellini V, Faunce DE, Gomez CR, Kovacs EJ. An age-associated increase in pulmonary inflammation after burn injury is abrogated by CXCR2 inhibition. J Leukoc Biol. 2008; 83:14931501. [PubMed: 18319289] Resolution of inflammation is slowed in aged rodents and is mediated by increased accumulation of neutrophils and tissue damage at the site of inflammation.

10. Weisel KC, Bautz F, Seitz G, Yildirim S, Kanz L, Mohle R. Modulation of CXC chemokine receptor expression and function in human neutrophils during aging in vitro suggests a role in their clearance from circulation. Mediators Inflamm. 2009; 2009:790174. [PubMed: 19390584]

11. Butcher SK, Chahal H, Nayak L, Sinclair A, Henriquez NV, Sapey E, O'Mahony D, Lord JM. Senescence in innate immune responses: reduced neutrophil phagocytic capacity and CD16 expression in elderly humans. J Leukoc Biol. 2001; 70:881-886. [PubMed: 11739550]

12. Wessels I, Jansen J, Rink L, Uciechowski P. Immunosenescence of polymorphonuclear neutrophils. ScientificWorldJournal. 10:145-160. [PubMed: 20098958]

13. Alvarez E, Ruiz-Gutierrez V, Sobrino F, Santa-Maria C. Age-related changes in membrane lipid composition, fluidity and respiratory burst in rat peritoneal neutrophils. Clin Exp Immunol. 2001; 124:95-102. [PubMed: 11359447]

14. Fortin CF, Lesur O, Fulop T Jr. Effects of aging on triggering receptor expressed on myeloid cells (TREM)-1-induced PMN functions. FEBS Lett. 2007; 581:1173-1178. [PubMed: 17336301]

15. Fulop T, Larbi A, Douziech N, Fortin C, Guerard KP, Lesur O, Khalil A, Dupuis G. Signal transduction and functional changes in neutrophils with aging. Aging Cell. 2004; 3:217-226. [PubMed: 15268755]

16. Mocchegiani E, Giacconi R, Cipriano C, Malavolta M. NK and NKT cells in aging and longevity: role of zinc and metallothioneins. J Clin Immunol. 2009; 29:416-425. [PubMed: 19408107] 
17. Mariani E, Neri S, Cattini L, Mocchegiani E, Malavolta M, Dedoussis GV, Kanoni S, Rink L, Jajte J, Facchini A. Effect of zinc supplementation on plasma IL- 6 and MCP-1 production and NK cell function in healthy elderly: interactive influence of +647 MT1a and-174 IL-6 polymorphic alleles. Exp Gerontol. 2008; 43:462-471. [PubMed: 18215484]

18. King AM, Keating P, Prabhu A, Blomberg BB, Riley RL. NK cells in the CD19- B220+ bone marrow fraction are increased in senescence and reduce E2A and surrogate light chain proteins in B cell precursors. Mech Ageing Dev. 2009; 130:384-392. [PubMed: 19428458] NK cells found in Hardy Fraction A in murine bone marrow are increased in aged mice and can downregulate E47 and $\lambda 5$ surrogate light chain expression. An intriguing report suggesting that NK cells on the bone marrow microenvironment can influence age-associated changes in B cell development.

19. Faunce DE, Palmer JL, Paskowicz KK, Witte PL, Kovacs EJ. CD1d-restricted NKT cells contribute to the age-associated decline of T cell immunity. J Immunol. 2005; 175:3102-3109. [PubMed: 16116199]

20. Inui T, Nakagawa R, Ohkura S, Habu Y, Koike Y, Motoki K, Kuranaga N, Fukasawa M, Shinomiya N, Seki S. Age-associated augmentation of the synthetic ligand-mediated function of mouse NK1.1 ag(+) T cells: their cytokine production and hepatotoxicity in vivo and in vitro. $\mathrm{J}$ Immunol. 2002; 169:6127-6132. [PubMed: 12444115]

21. Kawabata T, Kinoshita M, Inatsu A, Habu Y, Nakashima H, Shinomiya N, Seki S. Functional alterations of liver innate immunity of mice with aging in response to $\mathrm{CpG}$-oligodeoxynucleotide. Hepatology. 2008; 48:1586-1597. [PubMed: 18925636]

22. Stout-Delgado HW, Du W, Shirali AC, Booth CJ, Goldstein DR. Aging promotes neutrophilinduced mortality by augmenting IL-17 production during viral infection. Cell Host Microbe. 2009; 6:446-456. [PubMed: 19917499] Uses an HSV-2 infection model to demonstrate that increased IL-17 production by NKT cells contributes to increased mortality (largely from liver necrosis) in aged mice, suggesting an unanticipated role for elevated IL-17-mediated inflammation in the response to infections in aged individuals.

23. Tesar BM, Du W, Shirali AC, Walker WE, Shen H, Goldstein DR. Aging augments IL-17 T-cell alloimmune responses. Am J Transplant. 2009; 9:54-63. [PubMed: 18976294]

24. El Mezayen R, El Gazzar M, Myer R, High KP. Aging-dependent upregulation of IL-23p19 gene expression in dendritic cells is associated with differential transcription factor binding and histone modifications. Aging Cell. 2009; 8:553-565. [PubMed: 19624579] Provides further evidence for an age-associated increase in TH17-mediated inflammation. Reports an age-associated increase in IL-23 production and p19 gene expression in bone marrow-derived DCs from aged C57BL/6 mice, which is associated with $\mathrm{H} 3 \mathrm{~K} 4$ di- and tri-methylation (vs. tri-methylation in young DCs) and cRel occupancy (vs. both p65 and c-Rel in young DCs) at the p19 promoter.

25. Della Bella S, Bierti L, Presicce P, Arienti R, Valenti M, Saresella M, Vergani C, Villa ML. Peripheral blood dendritic cells and monocytes are differently regulated in the elderly. Clin Immunol. 2007; 122:220-228. [PubMed: 17101294]

25a. Leng SX, Xue QL, Tian J, Huang Y, Yeh SH, Fried LP. Associations of neutrophil and monocyte counts with frailty in community-dwelling disabled older women: results from the Women's Health and Aging Studies I. Exp Gerontol. 2009; 44:511-516. [PubMed: 19457449]

26. Boehmer ED, Goral J, Faunce DE, Kovacs EJ. Age-dependent decrease in Toll-like receptor 4mediated proinflammatory cytokine production and mitogen-activated protein kinase expression. $\mathrm{J}$ Leukoc Biol. 2004; 75:342-349. [PubMed: 14634059]

27. Boehmer ED, Meehan MJ, Cutro BT, Kovacs EJ. Aging negatively skews macrophage TLR2- and TLR4-mediated pro-inflammatory responses without affecting the IL-2-stimulated pathway. Mech Ageing Dev. 2005; 126:1305-1313. [PubMed: 16154177]

28. Chelvarajan RL, Collins SM, Van Willigen JM, Bondada S. The unresponsiveness of aged mice to polysaccharide antigens is a result of a defect in macrophage function. J Leukoc Biol. 2005; 77:503-512. [PubMed: 15629885]

29. Renshaw M, Rockwell J, Engleman C, Gewirtz A, Katz J, Sambhara S. Cutting Edge: Impaired Toll-Like Receptor Expression and Function in Aging. J Immunol. 2002; 169:4697-4701. [PubMed: 12391175] 
30. Chelvarajan RL, Liu Y, Popa D, Getchell ML, Getchell TV, Stromberg AJ, Bondada S. Molecular basis of age-associated cytokine dysregulation in LPS-stimulated macrophages. J Leukoc Biol. 2006; 79:1314-1327. [PubMed: 16603589]

31. Sebastian C, Herrero C, Serra M, Lloberas J, Blasco MA, Celada A. Telomere shortening and oxidative stress in aged macrophages results in impaired STAT5a phosphorylation. J Immunol. 2009; 183:2356-2364. [PubMed: 19605693]

32. van Duin D, Mohanty S, Thomas V, Ginter S, Montgomery RR, Fikrig E, Allore HG, Medzhitov R, Shaw AC. Age-associated defect in human TLR-1/2 function. J Immunol. 2007; 178:970-975. [PubMed: 17202359]

33. van Duin D, Allore HG, Mohanty S, Ginter S, Newman FK, Belshe RB, Medzhitov R, Shaw AC. Prevaccine determination of the expression of costimulatory B7 molecules in activated monocytes predicts influenza vaccine responses in young and older adults. J Infect Dis. 2007; 195:1590-1597. [PubMed: 17471428]

34. Agius E, Lacy KE, Vukmanovic-Stejic M, Jagger AL, Papageorgiou AP, Hall S, Reed JR, Curnow SJ, Fuentes-Duculan J, Buckley CD, et al. Decreased TNF-alpha synthesis by macrophages restricts cutaneous immunosurveillance by memory CD4+ T cells during aging. J Exp Med. 2009; 206:1929-1940. [PubMed: 19667063] A study evaluating human skin biopsy and skin suction blister specimens from young $(<40)$ and older $(>70)$ individuals that investigates the basis for ageassociated reductions in DTH responses. Age-associated reductions in TNF- $a$, IL- 6 and IFN- $\gamma$ in blister fluid, a reduction in TNF-a production in cutaneous macrophages and increase in cutaneous Treg cells are reported.

35. Franceschi C, Capri M, Monti D, Giunta S, Olivieri F, Sevini F, Panourgia MP, Invidia L, Celani L, Scurti M, et al. Inflammaging and anti-inflammaging: a systemic perspective on aging and longevity emerged from studies in humans. Mech Ageing Dev. 2007; 128:92-105. [PubMed: 17116321]

36. Kong KF, Delroux K, Wang X, Qian F, Arjona A, Malawista SE, Fikrig E, Montgomery RR. Dysregulation of TLR3 impairs the innate immune response to West Nile virus in the elderly. $\mathrm{J}$ Virol. 2008; 82:7613-7623. [PubMed: 18508883] An evaluation of West Nile Virus infection in human macrophages from young and elderly individuals. The down-regulation of TLR3 expression mediated by the interaction between the WNV envelope protein and DC-SIGN on macrophages and resultant STAT1 phophorylation is attenuated in cells from elderly individuals, potentially providing a basis for dysregulated TLR activation.

37. Gomez CR, Hirano S, Cutro BT, Birjandi S, Baila H, Nomellini V, Kovacs EJ. Advanced age exacerbates the pulmonary inflammatory response after lipopolysaccharide exposure. Crit Care Med. 2007; 35:246-251. [PubMed: 17133178]

38. Gomez CR, Nomellini V, Baila H, Oshima K, Kovacs EJ. Comparison of the effects of aging and IL-6 on the hepatic inflammatory response in two models of systemic injury: scald injury versus i.p. LPS administration. Shock. 2009; 31:178-184. [PubMed: 18636046]

39. Turnbull IR, Clark AT, Stromberg PE, Dixon DJ, Woolsey CA, Davis CG, Hotchkiss RS, Buchman TG, Coopersmith CM. Effects of aging on the immunopathologic response to sepsis. Crit Care Med. 2009; 37:1018-1023. [PubMed: 19237912]

40. Harper JM, Wilkinson JE, Miller RA. Macrophage migration inhibitory factor-knockout mice are long lived and respond to caloric restriction. Faseb J. 2010 published online March 24, 2010. Demonstration of unexpected lifespan prolongation in mice deficient in MIF a cytokine with proinflammatory, neuroendocrine, and cell cycle regulatory functions.

41. Grolleau-Julius A, Garg MR, Mo R, Stoolman LL, Yung RL. Effect of aging on bone marrowderived murine CD11c+CD4-CD8alpha- dendritic cell function. J Gerontol A Biol Sci Med Sci. 2006; 61:1039-1047. [PubMed: 17077196]

42. Tesar BM, Walker WE, Unternaehrer J, Joshi NS, Chandele A, Haynes L, Kaech S, Goldstein DR. Murine [corrected] myeloid dendritic cell-dependent toll-like receptor immunity is preserved with aging. Aging Cell. 2006; 5:473-486. [PubMed: 17129212]

43. Grolleau-Julius A, Harning EK, Abernathy LM, Yung RL. Impaired dendritic cell function in aging leads to defective antitumor immunity. Cancer Res. 2008; 68:6341-6349. [PubMed: 18676859] 
44. Stout-Delgado HW, Yang X, Walker WE, Tesar BM, Goldstein DR. Aging impairs IFN regulatory factor 7 up-regulation in plasmacytoid dendritic cells during TLR9 activation. J Immunol. 2008; 181:6747-6756. [PubMed: 18981092] Reports an age-associated defect in type I IFN production in $\mathrm{pDCs}$ purified from mouse bone marrow, using either in vitro stimulation of TLR9 or in vivo HSV-2 infection. The age-associated defect was associated with decreased IRF-7 upregulation, and could be partially rescued in calorically-restricted mice.

45. Allen CD, Cyster JG. Follicular dendritic cell networks of primary follicles and germinal centers: phenotype and function. Semin Immunol. 2008; 20:14-25. [PubMed: 18261920]

46. Aydar Y, Balogh P, Tew JG, Szakal AK. Follicular dendritic cells in aging, a"bottle-neck" in the humoral immune response. Ageing Res Rev. 2004; 3:15-29. [PubMed: 15163101]

47. Brown KL, Wathne GJ, Sales J, Bruce ME, Mabbott NA. The effects of host age on follicular dendritic cell status dramatically impair scrapie agent neuroinvasion in aged mice. J. Immunol. 2009; 183:5199-5207. [PubMed: 19786551]

48. Jing Y, Shaheen E, Drake RR, Chen N, Gravenstein S, Deng Y. Aging is associated with a numerical and functional decline in plasmacytoid dendritic cells, whereas myeloid dendritic cells are relatively unaltered in human peripheral blood. Hum Immunol. 2009; 70:777-784. [PubMed: 19596035]

49. Panda A, Qian F, Mohanty S, van Duin D, Newman FK, Zhang L, Chen S, Towle V, Belshe RB, Fikrig E, et al. Age-associated decrease in TLR function in primary human dendritic cells predicts influenza vaccine response. J Immunol. 2010; 184:2518-2527. [PubMed: 20100933] Reports a generalized, age-associated decrease in TLR-induced cytokine production in human mDCs and pDCs; TLR-induced cytokine production was strongly associated with protective antibody responses to influenza vaccination. Notably, elevated basal cytokine production was found in older, but not young individuals, suggesting constitutive cytokine expression that may not be substantially increased with subsequently TLR stimulation.

50. Agrawal A, Agrawal S, Cao JN, Su H, Osann K, Gupta S. Altered innate immune functioning of dendritic cells in elderly humans: a role of phosphoinositide 3-kinase-signaling pathway. J Immunol. 2007; 178:6912-6922. [PubMed: 17513740]

51. Agrawal A, Tay J, Ton S, Agrawal S, Gupta S. Increased reactivity of dendritic cells from aged subjects to self-antigen, the human DNA. J Immunol. 2009; 182:1138-1145. [PubMed: 19124757] Two references that report an age-associated increase in cytokine production in response to LPS, single-stranded RNA, or self-DNA stimulation of human monocyte-derived DCs, with accompanying defects in phagocytosis and migration in vitro.

52. Hazeldine J, Arlt W, Lord JM. Dehydroepiandrosterone as a regulator of immune cell function. J Steroid Biochem Mol Biol. 2010 In Press.

53. Radford DJ, Wang K, McNelis JC, Taylor AE, Hechenberger G, Hofmann J, Chahal H, Arlt W, Lord JM. Dehdyroepiandrosterone sulfate directly activates protein kinase C-beta to increase human neutrophil superoxide generation. Mol Endocrinol. 24:813-821. [PubMed: 20172962]

54. Butcher SK, Killampalli V, Lascelles D, Wang K, Alpar EK, Lord JM. Raised cortisol:DHEAS ratios in the elderly after injury: potential impact upon neutrophil function and immunity. Aging Cell. 2005; 4:319-324. [PubMed: 16300484] 


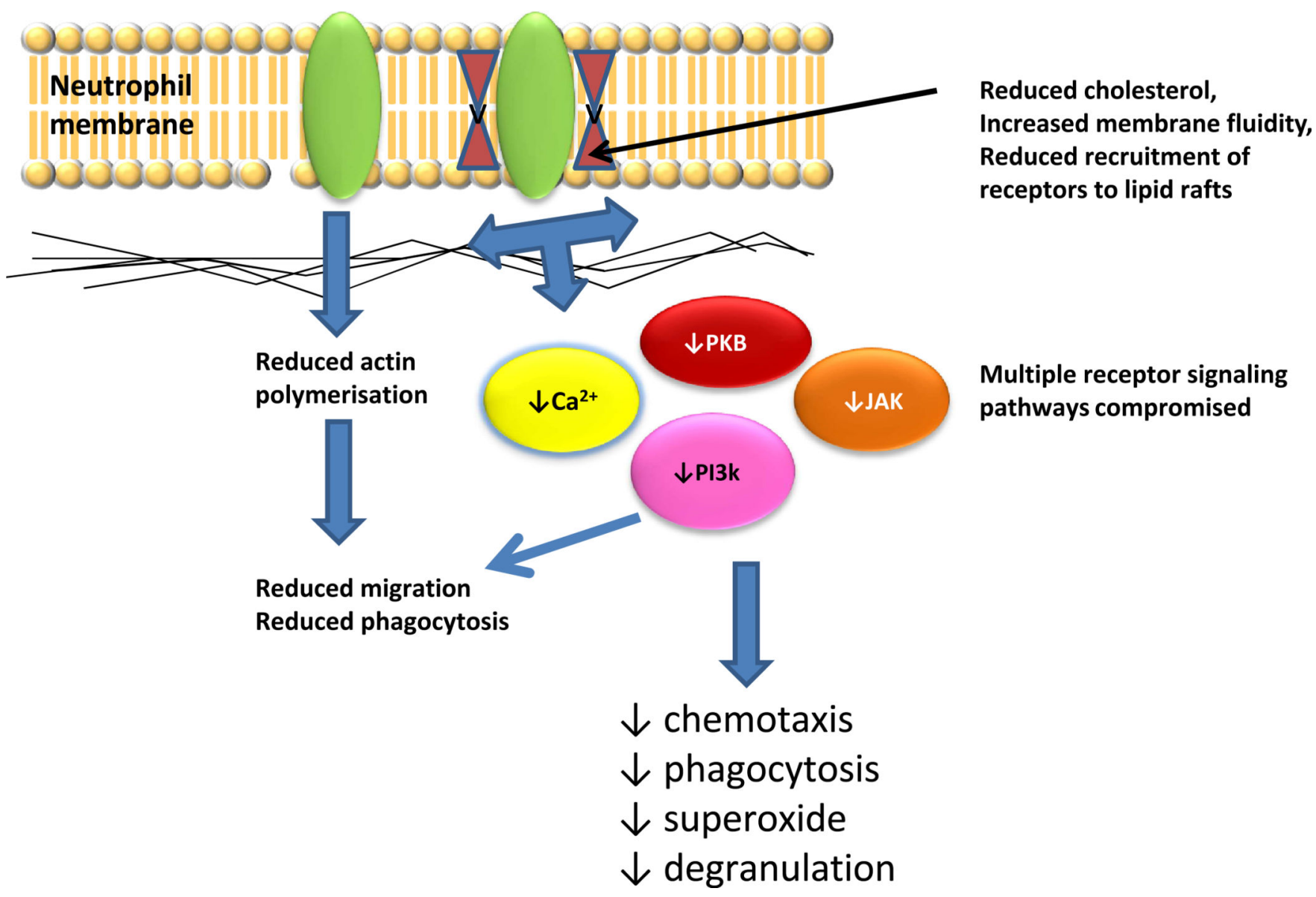

Figure 1. Consequences of altered membrane lipid content for neutrophil function Studies of peritoneal neutrophils from aged rats [13] have shown reduced levels of cholesterol and increased membrane fluidity, associated with reduced superoxide generating ability. Other studies have shown dysregulation of receptor recruitment to lipid rafts, which will have very broad effects in compromising receptor signaling functions and downstream biological effects. Abbreviations: PKB, protein kinase B; PI3K, phosphoinositide-3-kinase; JAK, JAK, JAK-STAT signaling (JAK, Janus kinase; STAT Signal Transducers and Activators of Transcription). 